\title{
Fibula çivisi
}

\author{
Fibula nail
}

\author{
Esat Uygur \\ İstanbul Medeniyet Üniversitesi, Tıp Fakültesi, Ortopedi ve Travmatoloji Ana Bilim Dalı, İstanbul; \\ Göztepe Prof. Dr. Süleyman Yalçın Şehir Hastanesi, Ortopedi ve Travmatoloji Kliniği, İstanbul
}

Buluş; tıbbın ortopedi ve travmatoloji alanında özellikle ayak bileği ekleminden uzak yerleşimli (Weber C) lateral malleol kırıklarının cerrahi tedavisinde tercih edilen hekim açısından tıbbi yazında kabul görmüş, etkin, az girişimsel, hızlı tedavi imkânı sunan; hasta açısından ise daha az ağrılı, hızlı iyileşme süreci ve hızlı işe dönme imkânı sunan tedavi yöntemidir. Kapalı cerrahi teknikle uygulanan fibula çivisi; çivi üzerindeki vida deliklerini belirleyen rehber düzenekle birlikte kullanılır. Fibula çivisinin distalinde iki adet farklı açılarda vida gönderebilme imkânı sunan vida deliği ve gerekli görüldüğü takdirde iki adet sindezmoz vidası gönderilmesi için vida delikleri bulundurmaktadır.

Anahtar sözcükler: fibula; lateral malleol; ayak bileği; kırık; implant; çivi; intrameduller

\section{T. C. Türk Patent Enstitüsü'ne Faydalı Model Belgesi için Başvuru Bilgileri ${ }^{[1]}$}

Başvuru bilgileri Tablo 1'de gösterilmiştir. ${ }^{[1]}$

Tablo 1. Başvuru bilgileri[1]

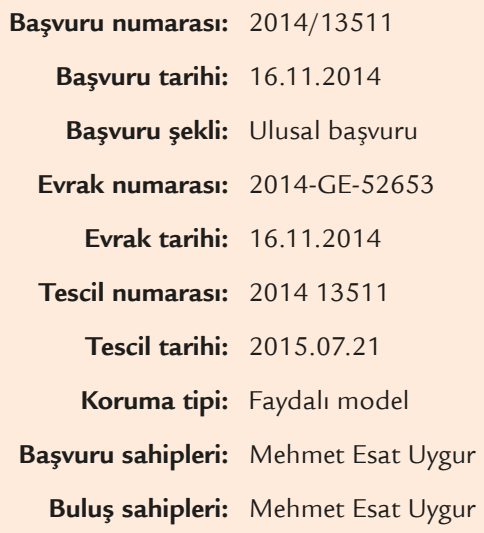

The invention is related especially to orthopedics and traumatology in the field of medicine. It is preferred to be used for the treatment of Weber $C$ lateral malleolus fractures. In terms of surgeons, it has been used by the surgeons and was approved by the literature. It is effective, minimal invasive and leads to rapid surgery and fast recovery. In terms of the patients, it is less painful, it leads to fast recovery and faster return to work. Fibula nail, which is applied with closed surgical technique; is used in conjunction with a guide device that identifies screw holes on the nail. It has a screw hole in the distal of the fibula nail, which allows to be send two screws at different angles, and screw holes for sending two syndesmosis screws if it is needed.

Key words: fibula; lateral malleolus; ankle; fracture; implant; nail; intramedullary
FAYDALI MODEL BELGESI - No: TR $201413511 Y^{[1]}$

\section{Teknik Alan ${ }^{[1]}$}

Buluş; tıp alanında ve yaralanma sonrası ayak bileği eklem hattından uzakta (Weber sınıflamasına göre C tipi kırıklar) gelişen lateral malleol kırıklarındaki cerrahi tedaviye yönelik intrameduller tespit malzemesi olarak kullanılacak bir cerrahi çivi ile ilgilidir.

\section{Önceki Teknik ${ }^{[1]}$}

"Ayak bileği yaralanmaları, ortopedi ve travmatoloji kliniklerinin acil servislerine en sık başvuru nedenidir. Yaralanmanın şiddetine göre ayak bileğinde kırıklar gelişebilir. Lateral malleol ise ayak bileği yaralanmaları sonrasında en sık kırılan kemiktir.

Lateral malleol kırıkları sonrasında her zaman cerrahi tedavi gerekmez. Cerrahi tedavi gereken durumlarda ise en çok tercih edilen yöntem açık ameliyatla plak vida kullanılarak

- İletişim adresi: Doç. Dr. Esat Uygur, İstanbul Medeniyet Üniversitesi, Göztepe Prof. Dr. Süleyman Yalçın Şehir Hastanesi, Ortopedi ve Travmatoloji Kliniği, İstanbul Tel: 0543 - 3160686 e-posta: esatuygur@gmail.com ORCID iD: 0000-0002-6900-1226

- Geliș tarihi: 5 Kasım $2020 \quad$ Kabul tarihi: 16 Kasım 2020 
yapılan cerrahidir. Weber $C$ seviyesinde gerçekleşen lateral malleol kırıklarında ise genellikle yine plak-vida sistemleri tercih edilirken nadiren kapalı tespit yöntemlerine başvurulur. Açık cerrahinin uygun görülmediği, cilt beslenmesinin iyi olmadığı ileri düzey yaralanmalarda ya da daha az girişimsel (minimal invaziv) olması amacıyla intrameduller çiviler önerilmektedir.”

\section{Buluşun Kısa Tarifi ${ }^{[1]}$}

"Bu buluşta sunulan fibula çivisinin mevcut intrameduller çivilere üstünlükleri ise:

- Çivinin alt ucu; fibula anatomisine uygun olacak şekilde 5,5 derece dışa (valgus) açılıdır.

- Farklı insan kemiklerine uyum sağlamak amacıyla çeşitli ebatlarda üretilmiş olması,

- Çivi üzerinden proksimal (üst) ve distal (alt) vidalar ile sindezmoz vidalarının gönderilmesi için rehber düzenekle birlikte kullanılması,

- Rehber düzenek eşliğinde bir adet önden arkaya oblik doğrultuda ve bir adet de arkadan öne oblik doğrultuda olmak üzere iki adet farklı yönelimli distal vidalama yapilabilmesi,

- Rehber düzenek eşliğinde gerek görüldüğ̈̈ takdirde iki sindezmoz vidası gönderilmesine imkân tanıması.

\section{Buluşun Amacı ${ }^{[1]}$}

"Buluşun amaçlarından ilki fibula çivisinin uygun şartlarda kullanılmasıyla etkin bir tedavi sağlamanın yanında; uygulama kolaylığı nedeniyle ortopedi ve travmatoloji cerrahına hız kazandırırken hastanın anestezi süresini kısaltmak, bu sayede anesteziye bağı riskleri azaltmaktır.

Diğer bir amacı hastada gelişebilecek iltihap ve yangı riskini azaltmaktır. Zira fibula çivisi kapalı cerrahi yöntem kullanılarak uygulandığından açık cerrahi yönteme kıyasla daha az iltihaplanma riski taşımaktadır.

Bir diğer amacı hasta konforunu sağlamak ve estetiğini korumaktır. Kapalı cerrahi yöntemde cilt kesileri daha küçük olduğundan hastanın ameliyat sonrası çektiği ıstırap daha az olduğu gibi cilt kesileri kozmetik olarak da daha makul bir görüntü sergilemektedir.

Bir diğer amacı implantın çıkarılmasına gerek kalmaması ya da çıkarılması durumunda hastaya yine daha az hasar vermek suretiyle çıkartma işleminin gerçekleştirilmesini mümkün kılmaktır. Çünkü lateral malleol cilde yakın olduğundan cerrahi sağaltımda plak-vida sistemi kullanıldığında implantların cildi rahatsız etmesi sık görülen bir durumdur. Bu durumda plak-vida sisteminin çıkarılması gerektiğinde önceki ameliyatta gerçekleştirilen cilt kesisi tekrarlanmak zorunda kalınır. Oysa fibula çivisi kemik içi yerleşimli olduğundan rahatsızlık vermesi beklenmez. Başka bir tıbbi nedenden ötürü çıkarılması gerekirse ilk ameliyatta gerçekleştirilen küçük cilt kesileri çivi çıkartma işlemi için yeterli olacaktır. Plak-vida sisteminde olduğu gibi cildi geniş olarak açmaya gerek yoktur.

Son olarak fibula çivisinin diğer bir amacı yukarıda bahsedilen durumlarla ilişkili olarak hastane masrafları ile sosyal güvenlik kurumu harcamalarını azaltmaktır. Nitekim daha küçük cilt kesileri nedeniyle nekahat dönemi daha kısa olacă̆ından hastanın hastanede kalıs süresi daha kısa, esenlendirmesi (rehabilitasyonu) daha kolay; daha erken işe geri dönmesi mümkün olacaktır. Implantın çıkarılmasına gerek kalmaması ve iltihap gibi ardıl sorunlarla karşılaşma riskinin daha az olması nedeniyle ikinci bir hastane masrafina ve iş gücü kaybına da gerek yoktur.”

\section{Buluşun Detaylı Açıklanması ${ }^{[1]}$}

"Fibula çivisi (Şekil 1); lateral malleol kırıklarının az girişimsel cerrahi tedavisine imkân verecek şekilde fibulanın (F) alt ucundan üst ucuna doğru (retrograd olarak) gönderilen, titanyum malzemesinden üretilen ortopedik implanttır.

Fibula çivisinin gövdesi; uç çapı 3,0 milimetre, 3,2 milimetre ve 3,4 milimetre olmak üzere farklı çaplarda ve 110 milimetre, 130 milimetre, 150 milimetre, 180 milimetre olmak üzere farklı uzunluklarda üretilmiş, ucu çentikli (10) fibular saptan (20) oluşmaktadır.

Fibular sap (20) üzerinde rehber düzenek eşliğinde distal kırık parçasının tespitini sağlayan vidaların (30) gönderileceği iki farklı yönelimli vida delikleri (40) bulunmaktadır.

Fibular sap (20) üzerinde rehber düzenek eşliğinde proksimal vidanın (50) tespitine imkan verecek proksimal vida deliği (60) bulunmaktadır.

Fibular sap (20) üzerinde gerek görüldüğünde sindezmoz vidası (70) gönderilmesine imkân verecek iki ayrı sindezmoz vida deliği (80) bulunmaktadır.

Bu cerrahi tasarım; vida göndermek maksadılla cilt üzerinden yapılan küçük kesilerin yerini fibula $(F)$ içerisindeki vida deliklerine denk getirmeyi sağlayan rehber gereç kullanılarak uygulanan malzemeler bütününden oluşmaktadır.

Buluşun uygulama esnasında gerçekleştirilecek işlem adımları şunlardır:

1- Hastanın ameliyat öncesi çekilen direk grafisi üzerinden çivi kalınlığı ve boyu hesaplanır.

2- Uygun görülen çivi rehber düzeneğine vidalanarak sabitlenir.

3- Lateral malleol kırığı (K) floroskopi rehberliğinde yerine yerleştirilir.

4- Lateral malleol (F) alt ucu hizasından uzunlamasına 0,5-1 santimetrelik cilt kesisini takiben fibula alt uси 
floroskopi cihazı rehberliğinde bulunarak kemik kabuğu biz ile delinir.

5- Fibula çivisi açılan delikten kemik içine yerleştirilir.

6- Rehber düzenek üzerindeki deliklerden geçirilen kanüllerin denk geldiği yerden küçük cilt kesileri yapılarak fibula (F) оуиси ile delinir. Distal vida delikleri (40) oyulurken oyucu, lateral malleol (F) içinde kalacak şekilde ilerletilirken sindezmoz vida deliği (80) oyulurken kaval kemiğine $(T)$ dek ilerletilir.
7- Rehber düzenek eşliğinde proksimal vida deliği (60) de oyulduktan vida boyları ölçülerek fibula çivisi kemiğe tespit edilir.

8- Floroskopi ile son kemik dizilimi kontrol edildikten sonra cilt kesileri kapatılarak ameliyat sonlandırılır.

Buluşun uygulama hedefi tıp alanındadır. Özellikle ayak bileği ekleminden uzak yerleşimli lateral malleol kırıklarının cerrahi tedavisinde önerilen fibula çivisi ortopedi ve travmatoloji cerrahlarının tercihine sunulur."

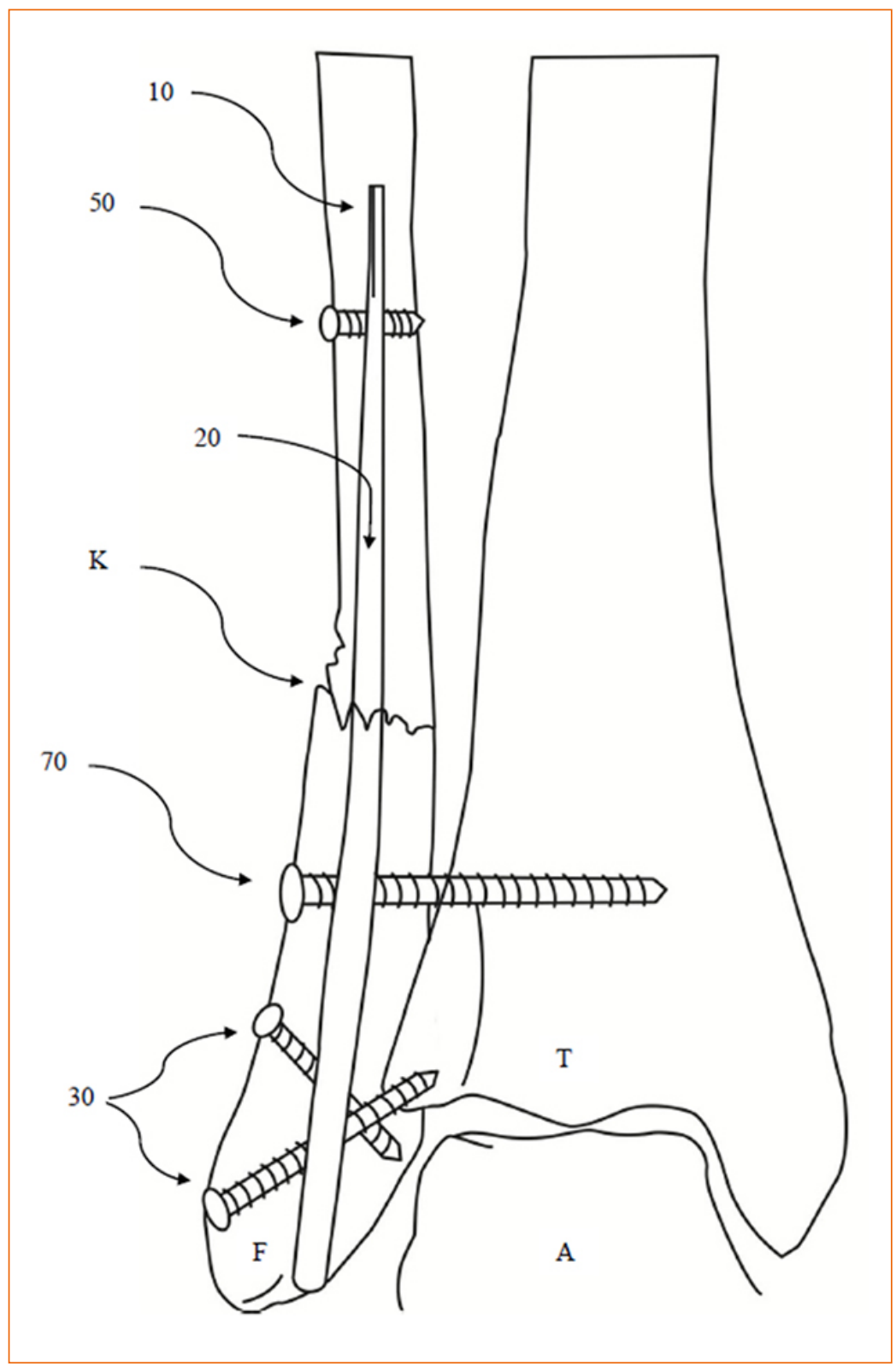

Şekil 1. Fibula çivisi (10, çentik; 50 , proksimal kilit vidası; 20 , fibular sap; $K$, lateral malleol kırık hattı; 70, sindezmoz vidaları; 30, distal kilit vidaları; F, fibula; $\mathrm{T}$, kaval kemiği [tibia]; A, aşık kemiği [talus]).

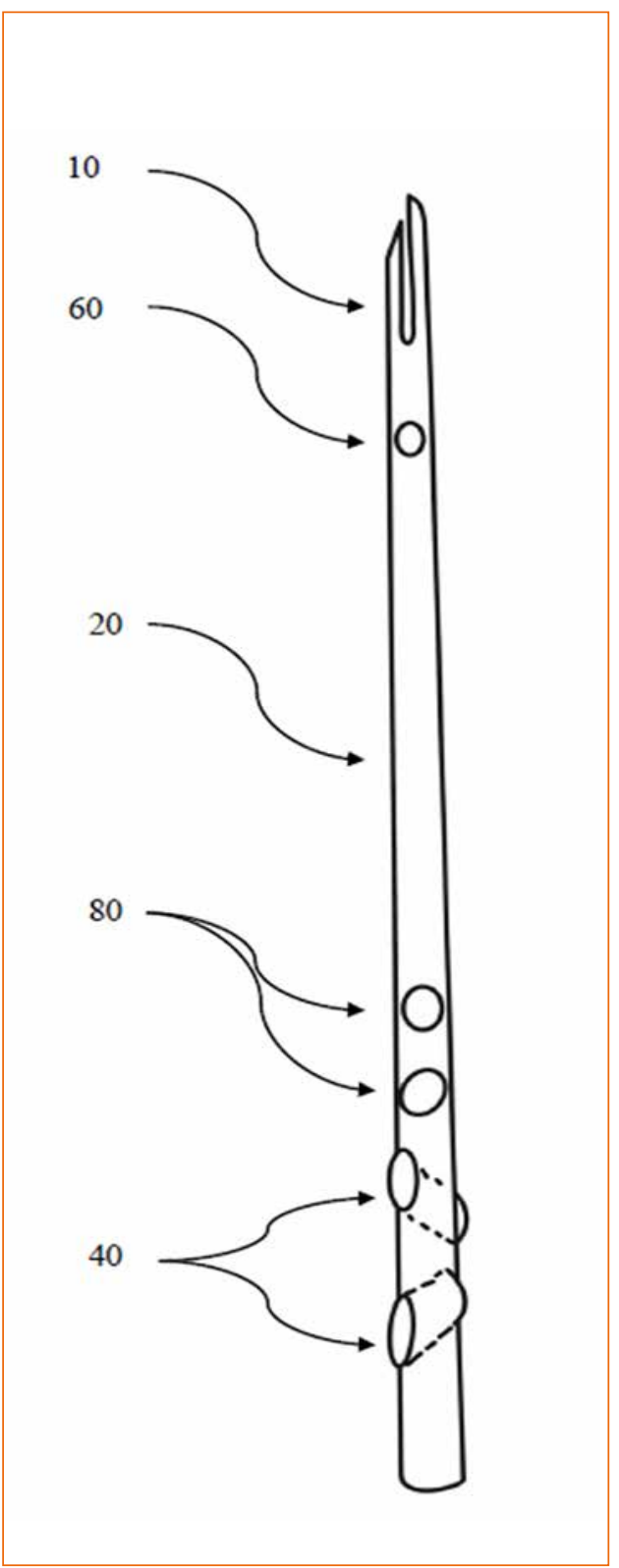

Şekil 2. Fibular sapın yandan görünüşü ( 10 , çentik; 60 , proksimal vida deliği; 20 , fibular sap; 80 , sindezmoz vida delikleri; 40, distal kilit vida delikleri). 


\section{İstemler ${ }^{[1]}$}

“1) Buluş, tıbbın ortopedi ve travmatoloji alanında kullanılan fibula çivisi olup özelliği ana gövdesinin titanyumdan üretilmiş, uygulama işleminde rehber düzeneğine tespit edilerek kullanılan fibular saptan (20) oluşmasıdır.

2) İstem 1'deki fibula çivisi olup özelliği; uç çapı 3,0 milimetre, 3,2 milimetre ve 3,4 milimetre olmak üzere farklı çaplarda; 110 milimetre, 130 milimetre, 150 milimetre ve 180 milimetre olmak üzere farklı uzunluklarda ve distalde 5,5 derece valgus açılı olarak üretilmiş fibular sap bulunmasidir.

3) Istem 1 veya 2'deki gibi bir ortopedik implant olup özelliği; proksimal (üst) ucunda çentik (10) bulunmasıdır.
4) Yukarıdaki istemlerden herhangi birindeki gibi bir ortopedik implant olup özelliği; üzerinde proksimal vida deliği (60), bir adet önden arkaya oblik doğrultuda ve bir adet de arkadan öne oblik doğrultuda olmak üzere iki adet farklı açılı distal vida delikleri (40) ve iki adet sindezmoz vida delikleri (80) bulunmasıdır."

\section{KAYNAK}

1. T.C. Türk Patent Enstitüsü. Faydalı Model belgesi. No: TR 201413511 Y. https://portal.turkpatent.gov.tr/anonim/ arastirma/patent/detayli 